\title{
Pressure Regulators as Valves for Saving Compressed Air and their Influence on System Dynamics
}

\author{
Lukáš Dvořák $^{1 \mathrm{a}}$, Kamil Fojtášek ${ }^{2}$ \\ ${ }^{1,2}$ VŠB-Technical University of Ostrava, Faculty of Mechanical Engineering, Department of Hydrodynamics and Hydraulic Equipment, \\ 17. listopadu 15/2172, Ostrava 70833, Czech Republic
}

\begin{abstract}
Pressure regulators in the field of pneumatic mechanisms can be used as valves for saving compressed air. For example it can be used to reduce the pressure when the piston rod is retracting unloaded and thus it is possible to save some energy. However the problem is that saving valve can significantly affect the dynamics of the pneumatic system. The lower pressure in the piston rod chamber causes extension of time for retraction of the piston rod. This article compare the air consumption experimentally determined and calculated, measured curves of pressure in cylinder chambers and piston speed when saving valve is set up differently.
\end{abstract}

\section{Introduction}

Pressure regulators, also known as pressure reducing valves, are used to reduce the pressure in pneumatic circuits. Typical example is that the valve reduces higher pressure of compressed air in tank to lower working pressure of pneumatic circuit. In this case pressure regulator is installed in a combined assembly of filter, regulator and sometimes lubricator. However, pressure regulators can be installed so that reduces pressure only in part of a pneumatic circuit. Application of pressure regulators are listed for example in [1]. One of many examples is the location of the regulator (combined valve ASR) between the directional control valve DV and pneumatic cylinder PC as it is shown in Figure1.

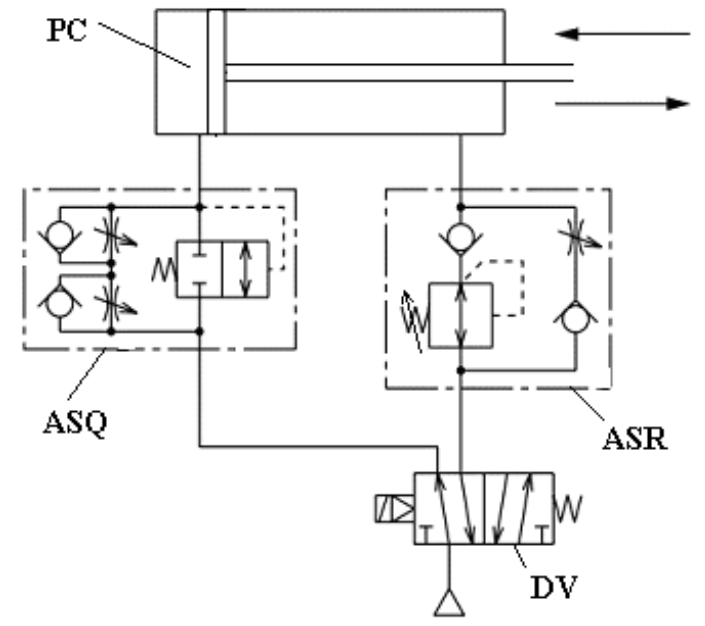

Figure 1. ASR and ASQ valves in pneumatic circuit [1]

\footnotetext{
${ }^{\mathrm{a}}$ Corresponding author: lukas.dvorak@vsb.cz
}

As we can see pressure regulator is combined with two check valves and throttling valve. This combined valve is supplied by SMC company under the name ASR valve. Some other companies supply similar valves. This combined valve ASR allows speed control by throttling valve during the extension stroke and reducing the pressure in the piston rod chamber during piston rod retracting. Pressure reduction is advantageous in the case where the piston rod retracts unloaded and compressed air only overcomes the friction of the piston and piston rod. Pressure reduction causes energy saving. According to pressure value for rod retraction is possible to save up to $40 \%$ of compressed air per working cycle of the cylinder. Examples of the savings will be shown below. ASR valve may be supplemented by ASQ valve, which is used to control the speed at the beginning of the extension stroke and vice versa when retracting the ends. Function of both valves is described in [2]

\section{Calculation and measurement of air consumption}

\subsection{Calculation of air consumption}

Because the volume of air depending on pressure and temperature, the calculation of air consumption is done so that the volume of the piston chamber and piston rod chamber must be converted to normal conditions. According to ISO / DIS5598 normal conditions are defined as temperature $t_{n}=20{ }^{\circ} \mathrm{C}(293.15 \mathrm{~K})$ and the pressure $p_{n}=1013$ mbar. The standard also prescribes writing of normal volume and volumetric flow rate unit behind unit of volume or flow should be added (ANR) which means atmospheric normal reference. For example normal cubic meter is marked as $\mathrm{m}^{3}$ (ANR). 
Air consumption $V_{c}$ per working cycle (extend and retract piston rod) can then be calculated from equation

$$
V_{c}=\left[\frac{\pi \cdot D^{2}}{4}+\frac{\pi \cdot\left(D^{2}-d^{2}\right)}{4}\right] \cdot s \cdot \frac{p_{1 a b s}}{p_{n}} \cdot \frac{T_{n}}{T_{1}}
$$

where $D$ is piston diameter, $\mathrm{m}, d$ piston rod diameter, $\mathrm{m}$, $s$ stroke of piston, $\mathrm{m}, p_{1 a b s}$ is absolute working pressure, $\mathrm{Pa}, \quad T_{1}$ working temperature of air, $\mathrm{K}$, and $p_{n}$ and $T_{n}$ are atmospheric normal references.

From equation 1 implies that the consumption of air depends not only on the size of the pneumatic cylinder but also to pressure and temperature. Operating temperature is usually close to normal temperature, so the temperature dependence of the volume is often ignored.

If we add pressure regulator to the pneumatic circuit, see Figure 1 or 2 , and we ignore the dependence on temperature, the equation for calculating the air consumption changes into the form

$$
V_{c}=\frac{\pi \cdot D^{2}}{4} \cdot s \cdot \frac{p_{1 a b s}}{p_{n}}+\frac{\pi \cdot\left(D^{2}-d^{2}\right)}{4} \cdot s \cdot \frac{p_{2 a b s}}{p_{n}}
$$

where $p_{2 a b s}$ is the pressure for retraction of the piston rod.

Equation to calculate the air consumption mentioned above show very good results. If we compare the results of calculation with measurement, error is within $5 \%$.

Some producers of pneumatic components suggest multiply results by constant of 1.4 intended to compensate thermodynamic losses. However, by comparing the calculation results and experimental results, this constant seems to be exaggerated because calculated air consumption is then about a $40 \%$ higher. It follows that the calculation according to equations 1 and 2 is sufficiently accurate.

\subsection{Experiment}

For verifying results of the calculation of air consumption and measure the dynamic characteristics of the experimental device was assembled, see scheme in Figure 2.

Equipment consisted of a pneumatic cylinder PC, directional control valve DV, pressure regulator ASR for reducing the pressure in the piston rod chamber and of the pressure regulator $\mathrm{RV}$ for adjusting the working pressure. Air consumption was determined by flowmeter QS. Further pressure in the chambers was measured by sensors PS1 and PS2 and also position by sensor PoS. Signals from the sensors were recorded by a measuring system HMG 3000.

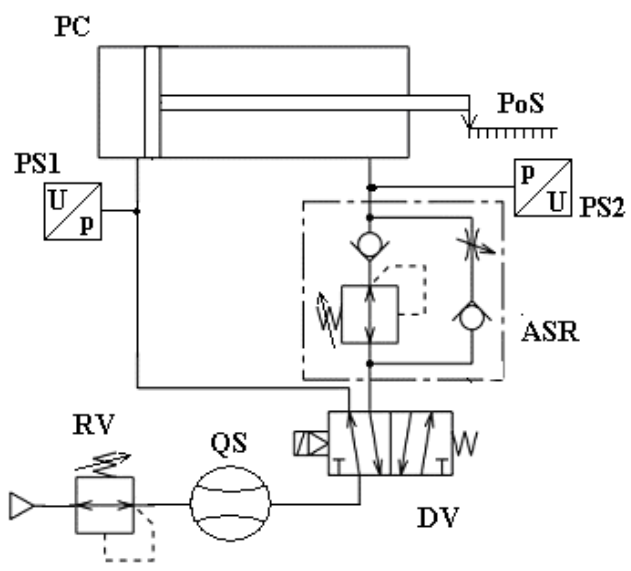

Figure 2. Scheme of experiment

Within the experiment, a number of measurements were performed with a cylinder diameter of 40 and stroke $500 \mathrm{~mm}$ and cylinder $63 / 250 \mathrm{~mm}$. Working pressure was set at 4 or 5 bar. Pressure for the piston rod retracting was varied from 1 to 2 bar. In the tables below are the results of measuring air consumption per cycle with and without valve including air savings expressed as a percentage.

\begin{tabular}{|c|c|c|c|c|c|}
\hline \multirow{2}{*}{$\begin{array}{l}\text { Working } \\
\text { pressure } \\
\text { bar }\end{array}$} & \multicolumn{2}{|c|}{ Air consumption } & \multirow{2}{*}{$\begin{array}{c}\text { Air saving } \\
\%\end{array}$} & \multirow{2}{*}{$\begin{array}{c}\text { Air } \\
\text { consumption } \\
\text { With valve set } \\
\text { on } 2 \text { bar } \\
\text { dm }^{3}(\text { ANR }) \\
\end{array}$} & \multirow{2}{*}{$\begin{array}{c}\text { Air saving } \\
\%\end{array}$} \\
\hline & $\begin{array}{l}\text { Without valve } \\
\mathrm{dm}^{3}\end{array}$ & $\begin{array}{c}\text { With valve set } \\
\text { on } 1 \text { bar } \\
\text { dm }^{3}(\mathrm{ANR}) \\
\end{array}$ & & & \\
\hline 4 & 6 & 4.06 & 32.3 & 4.84 & 19.3 \\
\hline 5 & 6.8 & 4.83 & 29.0 & 5.35 & 21.3 \\
\hline
\end{tabular}

Table 1. Air consumption of pneumatic cylinder $40 / 500$

\begin{tabular}{|c|c|c|c|c|c|}
\hline \multirow{2}{*}{$\begin{array}{l}\text { Working } \\
\text { pressure } \\
\text { bar }\end{array}$} & \multicolumn{2}{|c|}{ Air consumption } & \multirow{2}{*}{$\begin{array}{c}\text { Air saving } \\
\%\end{array}$} & \multirow{2}{*}{$\begin{array}{c}\text { Air } \\
\text { consumption } \\
\text { With valve set } \\
\text { on } 2 \text { bar } \\
\text { dm }^{3}(\text { ANR }) \\
\end{array}$} & \multirow{2}{*}{$\begin{array}{c}\text { Air saving } \\
\%\end{array}$} \\
\hline & $\begin{array}{l}\text { Without valve } \\
\qquad \mathrm{dm}^{3}\end{array}$ & $\begin{array}{c}\text { With valve set } \\
\text { on } 1 \text { bar } \\
\operatorname{dm}^{3}(\mathrm{ANR}) \\
\end{array}$ & & & \\
\hline 4 & 7.06 & 5.2 & 26.3 & 6.05 & 14.3 \\
\hline 5 & 8.92 & 6.05 & 32.2 & 6.86 & 23.1 \\
\hline
\end{tabular}

Table 2. Air consumption of pneumatic cylinder $63 / 250$ 
Pictures on this side shows the curve of pressure, stroke and speed when extending and retracting the piston rod. Working pressure was in all cases set to 4 bar.

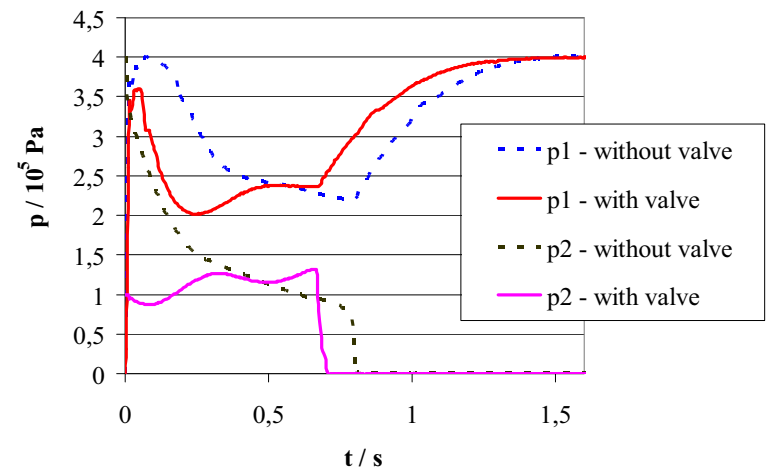

Figure 3. Extension - ASR 1 bar

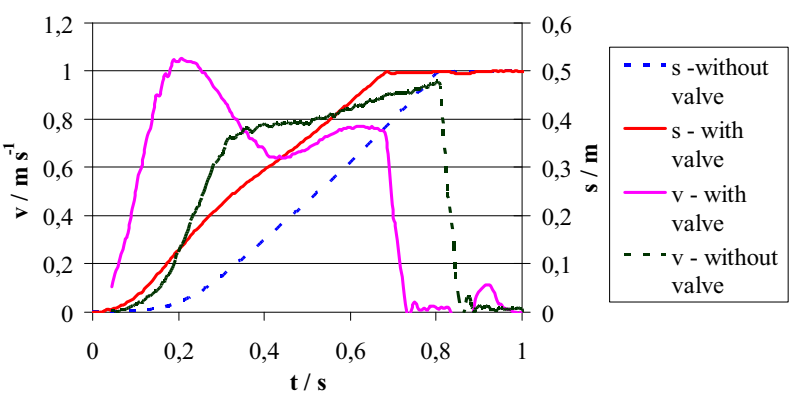

Figure 4. Extension - ASR 1 bar

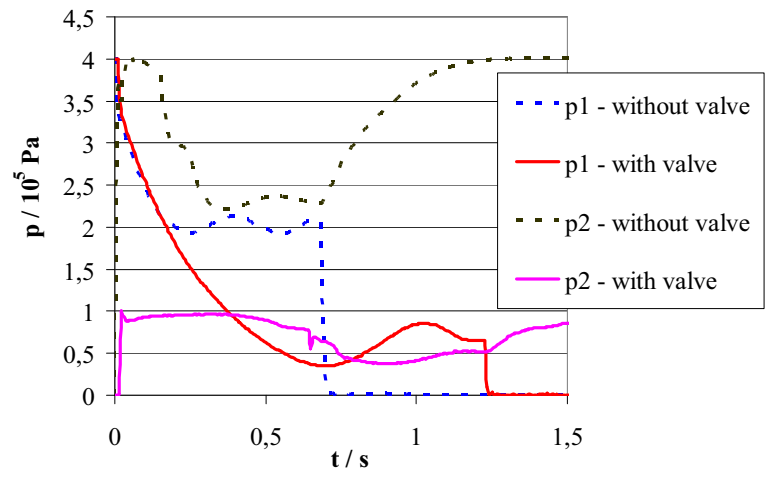

Figure 5. Retraction - ASR 1 bar

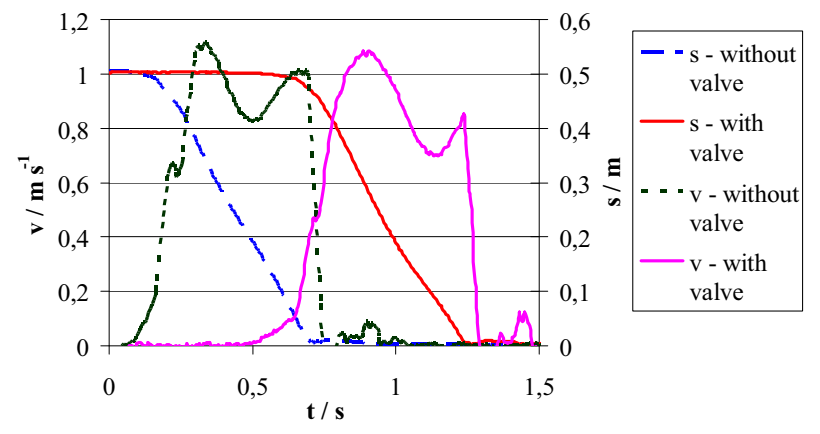

Figure 6. Retraction - ASR 1 bar
Note ASR - 1 bar or 2 bar means pressure value to retracting of piston rod set by the valve ASR.

In the figures are the results of measurements with a cylinder 40/500, see more [3].

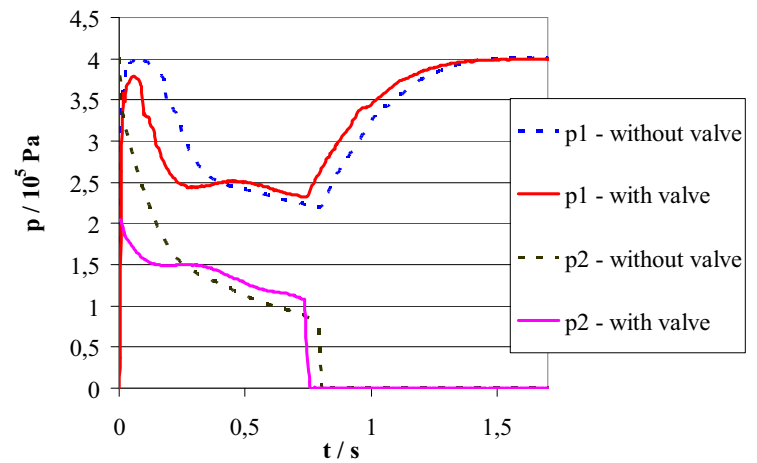

Figure 7. Extension - ASR 2 bar

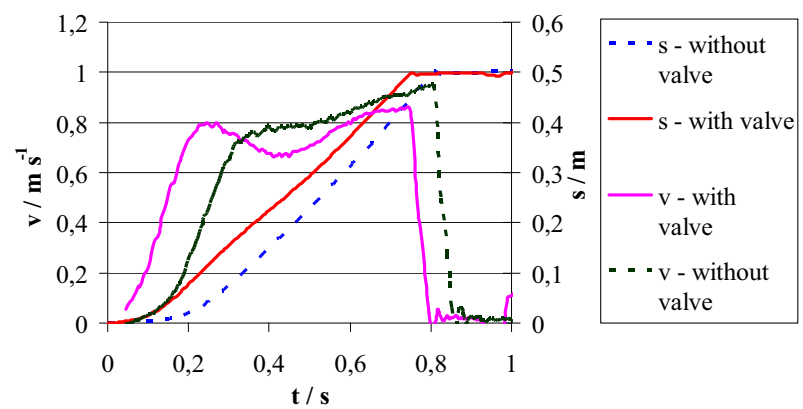

Figure 8. Extension - ASR 2 bar

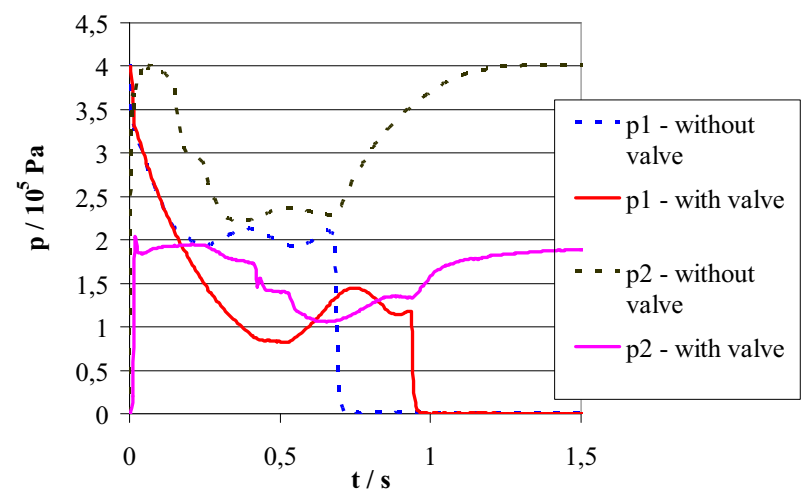

Figure 9. Retraction - ASR 2 bar

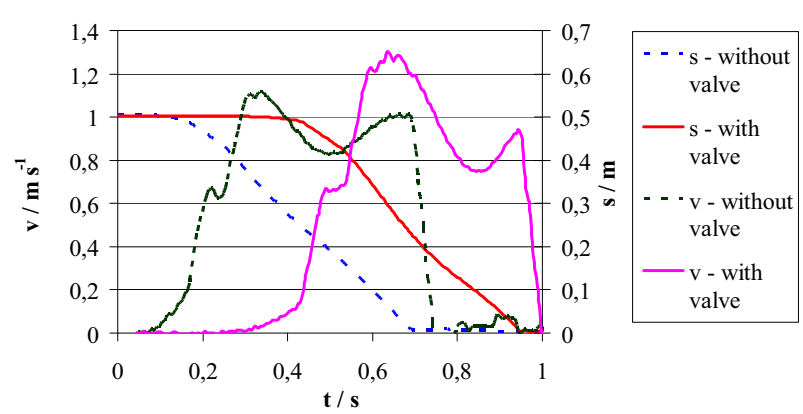

Figure 10. Retraction - ASR 2 bar 


\subsection{Comparison of the results}

From the measurement results of air consumption which are shown in Table 1 and 2 it follows that in these cases was the saving of air from 15 to $32 \%$. Energy saving depends on the size of the working pressure and settings of pressure regulator (ASR valve). When the valve is set to a lower pressure for the piston rod retraction it leads to saving more energy.

As already mentioned saving valves respectively lower pressure for rod retraction affects the dynamics of the pneumatic system. It is evident from Figures 3 to 10. Lower pressure $p_{2}$ in piston rod side chamber allows earlier start of piston rod movement, thereby shortening the total time of the stroke, see Figures 3 an 4 . With increasing pressure for the retraction this effect decreases, Figures 7 and 8. During retraction of the piston rod the lower pressure $p_{2}$ causes the opposite effect. In this case there is a delay in the movement of the piston rod and significantly extends the total time of stroke. For example, as we can see in Figures 5 and 6, start of piston rod moving in system without valve is at the time of $0.2 \mathrm{~s}$, in a system with energy-saving valve set at 1 bar is the start time of $0.6 \mathrm{~s}$. Total time for retraction is then without valve $0.7 \mathrm{~s}$ and with valve $1.25 \mathrm{~s}$. As is the case when piston rod extending also in this case, increasing pressure for retraction described effect decreases, Figures 9 and 10.

\section{Example of air savings}

Use of saving valves in the pneumatic system can bring significant savings of compressed air. We will look at an example of one pneumatic cylinder with a piston diameter of $63 \mathrm{~mm}$ and a stroke of $250 \mathrm{~mm}$. Working pressure in the pneumatic system will be 5 bar, saving valve will be set to 1 bar. We will consider continuous operation 24 hours a day. Number of cycles (extend and retract) per minute is 10 . From the measured values listed in the Table 2 follows air savings at the selected pressure $V_{s}=2.87 \mathrm{dm}^{3}$ (ANR) (air consumption without valve minus air consumption with valve). The cost of compression of one cubic meter of air at atmospheric pressure to working pressure is about $€ 0.023$. Under given conditions air saving is about 14880 cubic meters per year which corresponds finance saving about $€ 300$. In various production lines may be dozens of such pneumatic cylinders. Application of pressure regulators as saving valves can then bring a significant financial savings.

Table 3. Example of air savings

\begin{tabular}{|c|c|c|}
\hline \multirow{2}{*}{ Time interval } & Air savings & Financial savings \\
\cline { 2 - 3 } & $\mathrm{m}^{3}$ & EUR \\
\hline 1 cycle & 0.00287 & 0.00006 \\
\hline hour & 1.722 & 0.034 \\
\hline day & 41.3 & 0.827 \\
\hline month & 1239 & 25 \\
\hline year & 14878 & 298 \\
\hline
\end{tabular}

\section{Conclusion}

Pressure regulators are important components of pneumatic systems. Their primary task is to reduce the air pressure in the system and thereby control the force and torque of air motors. However, if regulator is appropriately involved in the circuit can also perform the function of saving valves. If during the retracting of piston rod cylinder performs no work it is appropriate to reduce pressure. According to pressure value for rod retraction is possible to save up to $40 \%$ of compressed air per working cycle of the cylinder. However, it is important to remember that reducing the pressure affects the total time of the stroke. With decreasing pressure extending the period of retraction of the piston rod. Therefore the application of saving valves should be always properly consider.

\section{References}

1. SMC Training - Stlačený vzduch a jeho využití. Brno, SMC Industrial Automation CZ s.r.o. 344 p.

2. SMC, Air Saving Valve, online, https://www.smc.eu/portal ssl/NEW EBP/13\%29F1 ow Control Equipment $/ 13.13 \% 29$ Air Saving_Valv e/a\%29ASR ASQ/ASR-ASQ EU.pdf

3. D. Král. Pressure Valves in Pneumatics: Bachelor Thesis. Ostrava: VŠB - TUO, 46 p. (2014)

\section{Acknowledgements}

This work was supported by the project SP2015/95 of VŠB-TU Ostrava.

\section{Nomenclature}

ASR pressure regulator combined with two check

valves and throttling valve

ASQ combined valve for flow control

d piston rod diameter

D piston diameter

DV directional control valve

$p_{1} \quad$ relative pressure in piston side chamber

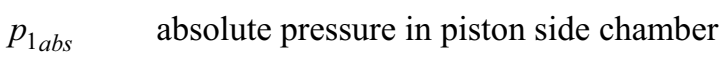

$p_{2} \quad$ relative pressure in piston rod side chamber

$p_{2 a b s} \quad$ absolute pressure in piston rod side chamber

PC pneumatic cylinder

PS pressure sensor

PoS position sensor

QS flow sensor

RV pressure regulator

$s \quad$ piston stroke

SMC producer of pneumatic components

$t$ time

$v \quad$ velocity

$V_{c} \quad$ air consumption per cycle

$V_{s} \quad$ air saving 